\title{
Depression and Associated Factors Among the Patients with Type 2 Diabetes in Rwanda.
}

\author{
Madeleine MUKESHIMANA ${ }^{1^{*}}$, and Geldine CHIRONDA ${ }^{2}$
}

\author{
OPEN ACCESS \\ Citation: Madeleine MUKESHIMANA1 \\ and Geldine CHIRONDA. Depression \\ and associated factors among the patients \\ with diabetes type 2 in Rwanda. Ethiop J \\ Health Sci. 2019; 29(6):709. \\ doi:http://dx.doi.org/10.4314/ejhs.v29 \\ i6.7 \\ Received: July 27, 2019 \\ Accepted: August 09, 2019 \\ Published: November 1, 2019 \\ Copyright: $\quad$ C2019 Madeleine \\ MUKESHIMANA1 and Geldine \\ CHIRONDA. This is an open access \\ article distributed under the terms of the \\ Creative Commons Attribution License, \\ which permits unrestricted use, \\ distribution, and reproduction in any \\ medium, provided the original author and \\ source are credited. \\ Funding:Rwanda Education Board \\ Competing Interests: The authors \\ declare that this manuscript was approved \\ by all authors in its form and that no \\ competing interest exists. \\ Affiliation and Correspondence: \\ ${ }^{1}$ Senior Lecturer, University of \\ Rwanda, College of Medicine and \\ Health Sciences \\ ${ }^{2}$ Senior Lecturer, Human Resource \\ for Health, University of Rwanda, \\ College of Medicine and Health \\ Sciences \\ *Email: angemado@gmail.com
}

\section{ABSTRACT}

Background: Various studies have found a greater prevalence of depression among patients having one or more chronic non communicable disease like diabetes mellitus than in the general population. This co-morbidity is linked with serious health consequences such as high mortality and morbidity, debility, low quality of life and increased health costs. The aim was to determine the prevalence of depression among patients with diabetes attending three selected district hospitals in Rwanda. Sociodemographic factors associated with depression were also explored. Methods: It was a descriptive cross sectional study. A sample of 385 was selected randomly to participate in the study and 339 complete the questionnaires making a response rate of $88 \%$. The Patient Health Questionnaire-9 (PHQ-9) was used to screen depression. Descriptive and inferential analysis were done.

Results: The majority of respondents $83.8 \% \quad(n=284)$ had depression. Among them $17.9 \%(n=61)$ had moderately severe to severe depression while $81.9 \%(n=223)$ had minimal to moderate depression. A statistically significant association was found between age and depression $(p=0.01)$ also between gender and depression ( $p=0.02)$. Significance was determined at $P<0.05$.

Conclusion: we found a high prevalence of depression among patients with diabetes. The regular screening of depression among these patients is recommended.

KEYWORDS: Co morbidity of depression with diabetes, depression, diabetes

\section{INTRODUCTION}

Different studies have confirmed the link between NonCommunicable Diseases (NCDs) and development of depression as well as other mental disorders with severe health consequences related to this co morbidity(1-4). According to the American Heart Association study; depression among patients with Cardio-vascular diseases was $17 \%, 23 \%$ was found in patients with cerebrovascular cases, $27 \%$ in diabetes patients and more than $40 \%$ of patients with cancer(5). Depression in patients with chronic non communicable diseases including cancer, diabetes mellitus, stroke or cardiovascular disease is $2-4$ - fold more prevalent than in people who do not have these diseases (3). 
Some of the health problems related to the comorbidity of depression and NCDs indicated in different global studies include high rate of mortality and morbidity, debility, low quality of life and increased cost of health as well as nonadherence to treatment $(4,6)$.

It is in this perspective that the World Health Organization (WHO) has endorsed the consistent screening of depression among patients with one or more NCDs (3). However, despite this recommendation for all countries depression continues to be less detected in chronic illnesses, largely because many health professionals focus more on physical complaint which is mostly the reason for the hospital visit, and forget the accompanying depression (7).

Rwanda as one of developing countries experiences an increase of non-communicable diseases (8). While statistics from WHO (9) show that communicable diseases constitute $90 \%$ of chief complaints in health care facilities in the country, depression estimated to prevail between $15 \%$ and $25 \%$ in the Rwandan population constitutes another significant health burden (10). Although the estimated co-morbidity of depression with NCDs in Rwanda is alarming where the prevalence of depression in patients with diabetes and hypertension is considered to be $27 \%$ and $29 \%$ respectively (10); there is no research based evidence that has been done in Rwanda to establish the co-morbidity of depression with NCDs. The first objective was to determine the prevalence of depression in patients with type 2 diabetes mellitus attending three selected district hospitals in Rwanda and the second objective was to identify the associated socio-demographic factors to this co-morbidity.

\section{MATERIALS AND METHODS}

Research design: Cross-sectional quantitative descriptive design was used to determine prevalence of depression among patients with type 2 diabetes mellitus and associated sociodemographic factors.

The sample size for the actual study was 385 participants and this size was calculated as follows, using the sample size formula given by Chow, Shao, and Wang (11).
Sample size calculation (prevalence of depression among diabetic/hypertensive patients): The sample size was calculated using the formula, $n=Z_{(1-\alpha / 2)}^{2} p q / d^{2}$ (where $Z_{(1-\alpha / 2)}=1.96$ at $95 \%$ confidence; $p=$ prevalence of depression; $q=1-p ; d=$ absolute allowable error (precision around the proportion to estimate; i.e. how wide the $95 \%$ confidence interval should be). For this study, we assumed maximum possible variability (i.e. $p=0.5 ; q=0.5$ ) and precision $(d) \pm 5 \%$ (i.e. the $95 \%$ confidence interval will have a width of $5 \%$ ). A total of 385 participants was targeted but only 339 participated making the response rate of $88 \%$.

Sample size (factors associated with depression): Group sample sizes of respondents in group one (depressed) and respondents in group two (non-depressed) achieve $80 \%$ power to detect a difference between the group proportions of 0.155 or $15.5 \%$. The proportion exposed to a given factor in group two (the non-depressed group) was assumed to be 0.50 or $50 \%$. The test statistic used was the two-sided $\mathrm{Z}$ test with pooled variance. The significance level of the test was targeted at 0.05 or $5 \%$ (11).

Sampling strategy: A systematic random sampling was used to choose the sample from the larger population which was all diabetic patients aged 21 years and above attending three selected district hospitals. Among these three hospitals, two of them were district hospitals from urban area and one from rural area with endocrinology and mental services. To obtain the systematic simple size; the sample size for each hospital was 128 participants for two hospitals and 129 for one hospital. This number was obtained by dividing the sample size for the study (385) by 3 (three hospitals) for equal distribution of participants. All registered diabetic patients at each of three hospitals scheduled for appointment during the period of data collection were then regarded as population size $(\mathrm{N})$. After obtaining the permission letter from the nurse in charge to access patient registry, the list was done for $(\mathrm{N})$ and code numbers were assigned starting from 1 for each hospital. The systematic random sample for each hospital was then obtained.

Data collection instruments: A Sociodemographic and medical information

DOI: http://dx.doi.org/10.4314/ejhs.v29i6.7 
questionnaire was constructed by the researchers to collect demographic data. Depression was screened using the PHQ-9. The PHQ-9, contains 9 items, it offers psychologists' concise, it is a selfadministered instrument that measure depression. It includes DSM-IV depression criteria with other major symptoms of depression into a brief selfreport tool that is globally used for diagnosing depression, as well as selecting and monitoring treatment (12).

PHQ-9 scoring: Patient completes PHQ-9 Quick Depression Assessment:

Scoring: Count the number (\#) of boxes checked in a column. Multiply that number by the value indicated below, then add the subtotal to produce a total score.

The possible range is $0-27$. Use the table below to interpret the PHQ-9 score

Not at all (\#) $\quad \times 0=$

Several days (\#) $\quad \times 1=$

More than half the days (\#) _

Nearly every day (\#) $\mathrm{x} 3=$

Total score

Table 1. Interpreting PHQ-9 Scores

\begin{tabular}{lll}
\hline $\begin{array}{l}\text { Total } \\
\text { score }\end{array}$ & $\begin{array}{l}\text { Depression } \\
\text { severity }\end{array}$ & Action \\
\hline $1-4$ & $\begin{array}{l}\text { Minimal } \\
\text { depression }\end{array}$ & $\begin{array}{l}\text { The score suggests the } \\
\text { patient may not need } \\
\text { depression treatment }\end{array}$ \\
$5-9$ & $\begin{array}{l}\text { Mild } \\
\text { depression } \\
\text { Moderate } \\
\text { depression }\end{array}$ & $\begin{array}{l}\text { judgment uses clinical } \\
\text { treatment based on } \\
\text { patient's duration of } \\
\text { symptoms and functional } \\
\text { impairment }\end{array}$ \\
10-14 & $\begin{array}{l}\text { Moderately } \\
\text { severe } \\
\text { depression } \\
\text { Severe } \\
\text { depressionts treatment for } \\
\text { depression, } \\
\text { antidepressant, using } \\
\text { psychotherapy and/or a } \\
\text { combination of treatment }\end{array}$ \\
\hline
\end{tabular}

Data collection procedures: Data was collected from three selected districts hospitals by the researcher with the help in each case of a research assistant who was a mental health nurse with a diploma in mental health nursing working at the respective study area hospital. At each of the selected hospitals the researcher and research assistant approached the endocrinology service in that hospital, asked permission to the nurse in charge to access the patient registry, and then identified patients scheduled for follow-up in a period of data collection. The researcher and research assistant made a list of those patients and selected a random sample of 128 patients for two of the hospitals and 129 patients for the third hospital using the systematic random sampling. After establishment of each random sample, the researcher and research assistant met each patient in the sample when they came for follow-up at the hospital. The meeting with the patient was held in a private room and the patient was requested by the researcher or research assistant to participate in the study, with the researcher explaining to the patient the purpose of the study and asking $\mathrm{him} /$ her to voluntary participate. The researcher collected the questionnaire back immediately once the patient finish to answer; this was taking approximatively 10 to 15 minutes. For those who could not read and write; the researcher interviewed them. Data was collected over a period of six weeks.

Data analysis: Data analysis was done using Stata 13. Cleaning of data was done before analysis. Calculation of frequencies was done to describe the sample. Normality of distribution and outliers for Data was checked. The prevalence of depression was estimated with $95 \%$ confidence intervals and was calculated using the PQH-9 table of score. After obtaining people's information about their mood, we calculated every participant's score over 9 items and we obtained the total mark over $27(9 * 3=27)$, then every participant was put under depression category based on the PHQ-9 score.

Categorical factors associated with depression were assessed using the standard Pearson's chisquare $(\chi 2)$ test. The fisher's exact test was used to measure this association if an expected cell count in the cross tabulation was less than 5 (sparse numbers).

Ethical considerations: The ethical clearances for the study were obtained from the University of KwaZulu Natal (REF/BO15/15); Rwanda Ministry

DOI: http://dx.doi.org/10.4314/ejhs.v29i6.7 
of Health (Ref: NHRC2015/PROT/018) and College of Medicine Health Sciences Institutional Review Board ((Ref: CMHS/IRB/66/2015). All participants voluntary consented to participate and signed the consent forms. During data collection, ethical considerations were respected by respecting the anonymity and confidentiality of participants; all participants were protected against any harm; the team of health care professionals composed by a registered nurse, a mental health nurse and medical doctor was in place to assist any person in need.

Table 2. Socio-Demographic Data

\section{RESULTS}

Demographic variables: The response rate was $88 \%$ as out of a sample size of 385 only 339 have answered the questionnaires. A high number of respondents was over 60 years $34 \% \quad(n=116)$. About 56\% ( $n=190)$ have been diagnosed with diabetes between 1 and 5 years. More than a half $56.9 \%(n=193)$ were married. The majority of respondents $78.5 \% \quad(n=266)$ were not employed and the majority were still living with their family $87.6 \%(\mathrm{n}=297)$. Also not few of participants 34.8 $(\mathrm{n}=198)$ never schooled (table 2$)$.

\begin{tabular}{|c|c|c|c|}
\hline Varible & & Number & percent \\
\hline \multirow[t]{5}{*}{ Age } & $21-30$ years & 29 & 8.5 \\
\hline & $31-40$ years & 58 & 17.1 \\
\hline & $41-50$ years & 48 & 14.1 \\
\hline & $51-60$ years & 88 & 25.9 \\
\hline & $>60$ years & 116 & 34.2 \\
\hline \multirow[t]{3}{*}{ Hospital } & Nyamata & 99 & 29.2 \\
\hline & Kibagabaga & 109 & 32.1 \\
\hline & Masaka & 131 & 38.5 \\
\hline \multirow[t]{2}{*}{ Gender } & Male & 73 & 21.5 \\
\hline & Female & 266 & 78.4 \\
\hline \multirow[t]{2}{*}{ Disease } & Diabetes type 2 & 339 & 100 \\
\hline & Hypertension & 21 & 6.2 \\
\hline \multirow[t]{4}{*}{ Duration of diabetes/hypertension } & $<1$ year & 49 & 14.4 \\
\hline & $1-5$ years & 190 & 56 \\
\hline & $6-10$ years & 67 & 19.7 \\
\hline & $>10$ years & 33 & 9.7 \\
\hline \multirow[t]{5}{*}{ Relationship status } & Single & 28 & 8.6 \\
\hline & Married & 193 & 56.9 \\
\hline & Divorced & 17 & 5.0 \\
\hline & Separated & 1 & 0.2 \\
\hline & Widow & 100 & 29.5 \\
\hline \multirow[t]{2}{*}{ Employment status } & Not employed & 266 & 78.4 \\
\hline & Employed & 73 & 21.5 \\
\hline \multirow[t]{3}{*}{ Who lived with the respondents } & Family & 297 & 87.6 \\
\hline & Friends & 12 & 3.5 \\
\hline & Live alone & 30 & 8.8 \\
\hline \multirow{6}{*}{ Educational level } & Never schooled & 118 & 34.8 \\
\hline & Not completed primary school & 83 & 24.4 \\
\hline & Completed the primary school & 53 & 15.6 \\
\hline & Not completed the secondary school & 51 & 15.0 \\
\hline & Completed the secondary school & 27 & 7.9 \\
\hline & Have a university level & 7 & 2.0 \\
\hline \multirow[t]{2}{*}{ Type of Medication } & Insulin & 43 & 12.6 \\
\hline & Pills & 296 & 87.3 \\
\hline
\end{tabular}

The results of depression screening using PHQ9: The participants' score about the PHQ-9 aimed at screening depression. All participants 100\% $(n=339)$ answered all questions. Every question

DOI: http://dx.doi.org/10.4314/ejhs.v29i6.7 
had a score note ranging from 0 to 3 . One third of participants $29.8 \%(\mathrm{n}=101)$ felt down, depressed and hopeless, while another third $29.8 \%(n=101)$ were having difficulties in their sleep with either trouble falling or staying asleep, or sleeping too much. Likewise, more than one third of participants $30.1 \%(n=102)$ felt tired or had a little energy. The table also indicates that more than a quarter of participants $18.9 \%(n=64)$ thought they would be better off dead or thought about hurting themselves Table 3).

Table 3: The results of depression screening using PHQ-9 (N=339).

\begin{tabular}{|c|c|c|c|c|c|c|c|c|c|c|}
\hline \multirow[t]{2}{*}{ Problems } & \multicolumn{2}{|c|}{$\begin{array}{l}\text { Nearly } \\
\text { every day } \\
3\end{array}$} & \multicolumn{2}{|c|}{$\begin{array}{l}\text { More than half } \\
\text { the days } \\
2\end{array}$} & \multicolumn{2}{|c|}{ Several days } & \multicolumn{2}{|c|}{ Not at all } & \multicolumn{2}{|c|}{$\begin{array}{l}\text { Total } \\
(\mathrm{N}=\mathbf{3 3 9})\end{array}$} \\
\hline & 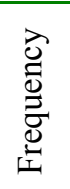 & $\%$ & 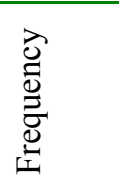 & $\%$ & 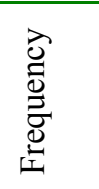 & $\%$ & 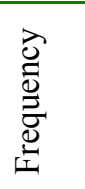 & $\%$ & 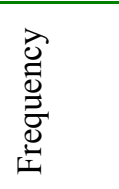 & $\%$ \\
\hline Little interest in doing things & 26 & 7.7 & 87 & 25.7 & 104 & 30.7 & 122 & 36 & 339 & 100 \\
\hline $\begin{array}{l}\text { Feeling down, depressed or } \\
\text { hopeless }\end{array}$ & 30 & 8.8 & 101 & 29.8 & 87 & 25.7 & 121 & 35.7 & 339 & 100 \\
\hline $\begin{array}{l}\text { Trouble falling or staying } \\
\text { asleep, or sleeping too much }\end{array}$ & 41 & 12.1 & 101 & 29.8 & 82 & 24.2 & 115 & 33.9 & 339 & 100 \\
\hline $\begin{array}{l}\text { Feeling tired or having little } \\
\text { energy }\end{array}$ & 43 & 12.7 & 102 & 30.1 & 97 & 28.6 & 97 & 28.6 & 339 & 100 \\
\hline Poor appetite or overeating & 24 & 7.1 & 85 & 25.1 & 87 & 25.7 & 143 & 42.2 & 339 & 100 \\
\hline $\begin{array}{l}\text { Feeling bad about yourself or } \\
\text { that you are a failure or have } \\
\text { let yourself or your family } \\
\text { down }\end{array}$ & 21 & 6.2 & 74 & 21.8 & 73 & 21.5 & 171 & 50.4 & 339 & 100 \\
\hline $\begin{array}{l}\text { Trouble concentrating on } \\
\text { things, such as reading the } \\
\text { newspaper or watching } \\
\text { television }\end{array}$ & 22 & 6.5 & 59 & 17.4 & 84 & 24.8 & 174 & 51.3 & 339 & 100 \\
\hline $\begin{array}{l}\text { Moving or speaking so slowly } \\
\text { that other people could have } \\
\text { noticed. Or the opposite being } \\
\text { so fidgety or restless that you } \\
\text { have been moving around a lot } \\
\text { more than usual }\end{array}$ & 26 & 7.7 & 52 & 15.3 & 87 & 25.7 & 174 & 51.3 & 339 & 100 \\
\hline $\begin{array}{l}\text { Thoughts that you would be } \\
\text { better off dead, or of hurting } \\
\text { yourself in some way }\end{array}$ & 8 & 2.4 & 26 & 7.7 & 38 & 11.2 & 267 & 78.8 & 339 & 100 \\
\hline
\end{tabular}

Prevalence of depression using PHQ-9 Scoring: The PQH-9 table score was used to measure the prevalence of depression. We found that the majority of participants $83.8 \%(=284)$ screened positive for depression. $17.9 \%(n=61)$ of those who screened positive had moderately severe to severe depression and the high number had minimal to moderate depression $81.9 \%(n=223)$. Few participants $16.2(\mathrm{n}=55)$ screened negative for depression (Table 4).

DOI: http://dx.doi.org/10.4314/ejhs.v29i6.7 
Table 4. Prevalence of depression using PHQ-9 Scoring.

\begin{tabular}{lll} 
Depression categories & Frequency & $\mathbf{\%}$ \\
\hline No depression & 55 & 16.2 \\
Minimal depression & $\mathbf{5 6}$ & 16.5 \\
Mild depression & $\mathbf{9 5}$ & 28.0 \\
Moderate depression & $\mathbf{7 2}$ & 21.2 \\
Moderately severe depression & $\mathbf{3 9}$ & 11.5 \\
Severe depression & $\mathbf{2 2}$ & 6.4 \\
\hline
\end{tabular}

Socio- Demographic factors associated with depression: In our findings, a statistically significant association was found between age and depression $(p=0.01)$. The relative risk for depression was almost twice among respondents aged between 31-40 years old compared to those aged between 21-30 years old [odds ratio $(\mathrm{OR})=$ 1.5 and $95 \% \mathrm{CI}=0.51-4.54]$; the relative risk was more higher among respondents aged between 4150 years old compared to those aged between 21$30(\mathrm{OR}=14.9$ and $95 \% \mathrm{CI}=1.73-129)$.

Table 5: Association between Socio-Demographic factors and depression

\begin{tabular}{|c|c|c|c|c|c|}
\hline \multicolumn{2}{|c|}{ Socio-Demographic factors } & \multirow{2}{*}{$\begin{array}{l}\text { Depression } \\
\mathrm{N}(\%) \\
22(75.9)\end{array}$} & \multirow{2}{*}{$\begin{array}{l}\text { No } \\
\text { depression } \\
\text { N(\%) } \\
7(24.1\end{array}$} & \multirow{2}{*}{$\begin{array}{c}\text { OR }(95 \% . \text { CI }) \\
1\end{array}$} & \multirow[t]{2}{*}{ P value } \\
\hline Age & 21-30 years & & & & \\
\hline & $31-40$ years & $48(82.8)$ & $10(17.2)$ & $1.53(0.51-4.54)$ & 0.446 \\
\hline & $41-50$ years & $47(97.9$ & $1(2.1)$ & $14.95(1.73-129)$ & 0.014 \\
\hline & $51-60$ years & $75(85.2$ & $13(14.8)$ & $1.83(0.65-5.16)$ & 0.250 \\
\hline & $>60$ years & $92(79.3)$ & $24(20.7)$ & $1.21(0.46-3.19)$ & 0.68 \\
\hline \multirow{2}{*}{ Gender } & Male & $55(75.3)$ & $18(24.7)$ & 1 & \\
\hline & Female & $229(86.1)$ & $37(13.9)$ & 2.02(1.79-5.22) & 0.029 \\
\hline \multirow[t]{5}{*}{ Relationship status } & Single & $22(78.6)$ & $6(21.4)$ & 1 & \\
\hline & Married & $158(81.9)$ & $35(18.1)$ & $1.23(0.46-3.26)$ & 0.67 \\
\hline & Divorced & $16(94.1)$ & $1(5.9)$ & $4.36(0.47-39.8)$ & 0.19 \\
\hline & Separated & $1(100)$ & $0(0)$ & 1 & \\
\hline & Widow & $87(87)$ & $13(13)$ & $1.82(0.62-5.34)$ & 0.27 \\
\hline \multirow[t]{2}{*}{ Employment status } & Not employed & $226(85)$ & $40(15)$ & 1 & \\
\hline & Employed & $58(79.5)$ & $15(20.5)$ & $0.68(0.35-1.32)$ & 0.26 \\
\hline \multirow{3}{*}{$\begin{array}{l}\text { Who lived with the } \\
\text { respondents }\end{array}$} & Family & $252(84.8)$ & $45(15.2)$ & 1 & \\
\hline & Friends & $9(75.0)$ & $3(25.0)$ & $0.53(0.13-2.05)$ & 0.36 \\
\hline & Live alone & $23(76.7)$ & $7(23.3)$ & $0.58(0.23-1.44)$ & 0.24 \\
\hline \multirow[t]{6}{*}{ Educational level } & Never schooled & $99(83.9)$ & $19(16.1)$ & 1 & \\
\hline & $\begin{array}{l}\text { Not completed the } \\
\text { primary school }\end{array}$ & $73(88.0)$ & $10(12.0)$ & $1.40(0.61-3.19)$ & 0.42 \\
\hline & $\begin{array}{l}\text { Completed the primary } \\
\text { school }\end{array}$ & $45(84.9)$ & $8(15.1)$ & $1.07(0.43-2.65)$ & 0.86 \\
\hline & $\begin{array}{l}\text { Not completed the } \\
\text { secondary school }\end{array}$ & $42(82.4)$ & $9(17.6)$ & $0.89(0.37-2.14)$ & 0.80 \\
\hline & $\begin{array}{l}\text { Completed the } \\
\text { secondary school }\end{array}$ & $20(74.1)$ & $7(25.1)$ & $0.54(0.20-1.47)$ & 0.23 \\
\hline & Have a university level & $5(71.4)$ & $2(28.6)$ & $0.47(0.86-2.65)$ & 0.40 \\
\hline Duration of & $<1$ year & $39(79.6)$ & $10(20.4)$ & 1 & \\
\hline \multirow[t]{3}{*}{ diabetes/Hypertension } & $1-5$ years & $158(83.2)$ & $32(16.8)$ & $1.26(0.57-2.79)$ & 0.55 \\
\hline & $6-10$ years & $57(85.1)$ & $10(14.9)$ & $1.46(0.55-3.82)$ & 0.44 \\
\hline & $>10$ years & $30(90.9)$ & $3(9.1)$ & $2.56(0.64-10.10)$ & 0.18 \\
\hline \multirow{2}{*}{$\begin{array}{l}\text { Type of medication } \\
\text { used }\end{array}$} & Insulin & $34(79.1)$ & $9(20.9)$ & 1 & \\
\hline & Pills & $250(84.5)$ & $46(15.5)$ & $1.43(0.64-3.19)$ & 0.37 \\
\hline
\end{tabular}

DOI: http://dx.doi.org/10.4314/ejhs.v29i6.7 
Also, a significant association was found between gender and depression $(p=0.02)$. Depression was higher in females than males. The relative risk of depression was twice among females respondents compared to males $(\mathrm{OR}=2.02$ and $95 \% \mathrm{CI}=$ 1.07-3.82). Nevertheless no significant associations was found between depression and other socio-demographic factors. The following are $p$-values found between depression and relationship status $(\mathrm{p}=0.49)$; employment status $(\mathrm{p}=0.17)$, who lived with the respondents $(p=0.28)$; educational level $(p=0.49)$; duration of diabetes/hypertension $(\mathrm{p}=0.57)$ and types of medication used ( $\mathrm{p}=0.37$ ) (Table 5).

Additionally, binary logistic regression analysis was conducted to ascertain the relationship between depression and other variables including patients' age and gender. Taking patients aged 21-30 years as reference, patients aged 41-50 have 13 times higher risks of depression $\quad \mathrm{OR}=13.4, \quad(95 \% \mathrm{CI}: \quad 1.54-116.41)$, $\mathrm{p}=0.019$. In addition, female patients are 2 times higher risks of depression compared to males, $\mathrm{OR}=1.94$, (95\%CI: 1.01-3.74), $\mathrm{p}=0.046$ (Table 6).

Table 6. Logistic regression analysis of depression prevalence in relation patients' age and gender.

\begin{tabular}{|c|c|c|c|c|c|c|}
\hline Depression & Odds Ratio & Std. Err. & $\bar{Z}$ & $\overline{\mathbf{P}>|\mathbf{z}|}$ & {$[95 \%$ Conf. } & erval] \\
\hline \multicolumn{7}{|l|}{ Age } \\
\hline $21-30$ & 1 & & & & & \\
\hline $31-40$ & 1.482941 & 0.83221 & 0.7 & 0.483 & 0.493673 & 4.454601 \\
\hline $41-50$ & 13.38781 & 14.77341 & 2.35 & 0.019 & 1.53961 & 116.4148 \\
\hline $51-60$ & 1.64445 & 0.880053 & 0.93 & 0.353 & 0.576086 & 4.69412 \\
\hline$>60$ & 1.093592 & 0.545359 & 0.18 & 0.858 & 0.411503 & 2.906281 \\
\hline \multicolumn{7}{|l|}{ Gender } \\
\hline Male & 1 & & & & & \\
\hline Female & 1.946858 & 0.649602 & 2 & 0.046 & 1.012317 & 3.744139 \\
\hline
\end{tabular}

\section{DISCUSSION}

Prevalence of depression among diabetic patients: The aim of the current study was to determine the prevalence of depression among patients with diabetes attending three selected district hospitals in Rwanda. The results revealed that the majority of respondents $83.8 \% \quad(n=284)$ had depression ranging from minimal to severe depression corroborating what was reported in an international study of one year done in 60 countries to determine the prevalence of depression among 245,400 patients with chronic diseases. Depression among patients with type 2 Diabetes Mellitus has been also found by different researchers in different countries and settings. Zhang, Xu, Zhao, Yin, Wang, Guo et al., (13) found a prevalence rate of $5.7 \%$ of depression among patients with type 2 diabetes. Also, Sweileh, Abu-Hadeed, Al-Jabi, and Sa'ed (14) found a prevalence rate of depression of $40 \%$ among diabetic patients in his cross-sectional done in Palestine. In their study Igwe, Uwakwe, Ahanotu, Onyeama, Bakare and Ndukuba (15) found depression to be $27.8 \%$ and $26.7 \%$ among patients with diabetes and Hypertension respectively.

Additionally, the results from a study done in Jordan revealed a prevalence rate of undiagnosed depression among diabetic patients to be $19.7 \%$ (1). Another study done in India by Raval, Dhanaraj, Bhansali, Grover and Tiwari (16) found that $41 \%$ of diabetic patients were diagnosed to have depression. Also prevalence of depression $(44 \%)$ was found among patients with diabetes type 2 in a study by Khuwaja, Lalani, Dhanani, Azam, Rafique and White (17) .

Examples above show a relatively low prevalence rate of depression than one found in 
our study. However, there are studies which have also found a high prevalence rate of depression in participants with diabetes Mellitus type 2 ranging from $41 \%$ to $83 \%(14,18,19)$

In the study done by Khan and colleagues (20) the overall prevalence of depression among diabetes patients was $87 \%$.

From our point of view we think that the high prevalence rate of depression in our study may be attributed to the tragic event of genocide as this has affected many Rwandans making them vulnerable to anxiety as well as depression. Besides, differences in prevalence of depression in many studies have been attributed to the use of different instruments to screen depression (14).

In the current study, the results found that $6.4 \%(n=22)$ had severe depression. In his study Aboshaiqah (21) found that $18.4 \%(n=83)$ of participants had severe depressive symptoms. The results from American Heart Association about major depression in patients with cardiovascular diseases; cerebrovascular diseases; diabetes and cancer were $17 \% ; 23 \% ; 27 \%$; and $40 \%$ respectively (5). Additionally, Raval et al., (16) found that $23 \%$ of patients with type 2 met the criteria for severe depression.

Compared to the above mentioned findings, our study found a smaller percentage of severe depression. This may be because diabetes was well controlled in our participants and our sample excluded participants with diabetes complications. However, these results are in accordance with those found by Arambewela and colleagues (22) who reported that major depression was found at the low prevalence rate of $4 \%$ in patients with diabetes.

In the current study, $39.1 \%(n=133)$ had moderate to severe depression; $28 \%(\mathrm{n}=95)$ had mild depression while $16.5 \%(\mathrm{n}=56)$ had minimal depression. Only $16.2 \quad(\mathrm{n}=55)$ did not have depression. The results are in line with those found by Aboshaiqah (21) who noted that 25.2\% of the patients in his study reported to have moderate to severe depressive symptoms, and about $13.8 \%$ of those participants reported to have experienced mild level of depression in his study to determine Correlates of depression among clients with Chronic illnesses in Saudi Arabia. Likewise, Raval et al., (16) reported $18 \%$ of moderate depression among patients with diabetes type 2.

Factors associated with depression: The current study found a statistically significant association between age and depression $(p=0.01)$. Older age was associated with high prevalence rate of depression. The relative risk for depression was almost twice among respondents aged between 3140 years old compared to those aged between 21 30 years old [odds ratio $(\mathrm{OR}=1.5$ and $95 \% \mathrm{CI}=$ $0.51-4.54]$; the relative risk was more higher among respondents aged between 41-50years old compared to those aged between 21-30 (OR=14.9 and $95 \% \mathrm{CI}=1.73-129)$. A statistically significant association between gender and depression $(p=0.02)$ was also found. Depression was higher in females than males. The relative risk of depression was twice among females respondents compared to males $(\mathrm{OR}=2.02$ and $95 \% \mathrm{CI}=1.07-3.82)$. However there was no statistically significant associations found between the rest of socialdemographic factors explored in our study and depression namely relationship status, employment status, who lived with the respondents, educational level, duration of diabetes/hypertension, and types of medication used. The results are in agreement with those found by Arambewela (22) who found a significant association between gender and depression((OR 2.63， 95\% CI 1.26-5.46; $\mathrm{P}=0.009)$, . Unlike in our study, these authors found a significant association between living without a spouse (single/divorced/widowed) (OR $1.83,95 \%$ CI $1.12-2.98 ; \mathrm{P}=0.01$ ) and lower education level (OR 1.92, 95\% CI 1.14-3.22; $\mathrm{P}=0.01$ ) with depression. . Also in their study to determine depression and its association with socidemographic characteristics Rahman and colleagues (23) found that females were more depressed than males. Also this was reported by Mahalli (24) who found out that females were more depressed than males. In the study Habtewold and colleagues (25) found out that age was significantly associated with depression.

The results from our study are not in accord with the results from the study done by Igwe et al., (15) who found a significant association between educational level and depression $(p=<0.001)$. They found that depression was higher in patients with

DOI: http://dx.doi.org/10.4314/ejhs.v29i6.2 
no education. The same authors found a significant relationship between relationship status and employment status with depression $(p<0.001)$; they found that depression was higher in respondents with diabetes mellitus if they were not married, and were not employed. Similarly, in his study Aboshaiqah (21) found that there was no significant difference between male and female patients in their depressive symptoms $(\mathrm{t}=-0.69, \mathrm{p}$ $=0.488)$.

Basing on the results found in this study; particularly a considerable prevalence rate of depression among respondents $83 \%(\mathrm{n}=284)$; socio-demographic factors associated with this condition which are age and gender; we recommend for regular depression screening among patients with diabetes as well as other chronic illnesses in Rwanda district hospitals. This will decrease the number of the depressed or the misrecognized depressed patients who are also consulting for one or more chronic illness and subsequently offer them a better quality health care for this co-morbidity.

\section{ACKNOWLEDMENTS}

The authors thank the University of KwaZulu Natal, Rwanda Ministry of Health and Institutional Review Board from University of Rwanda for their ethical approval to conduct the study.

\section{REFERENCES}

1. Al-Amer RM, Sobeh MM, Zayed AA, Aldomi HA. Depression among adults with diabetes in Jordan: risk factors and relationship to blood sugar control. Journal of Diabetes and its Complications. 2011;25(4):247-52.

2. Gunn JM, Ayton DR, Densley K, Pallant JF, Chondros P, Herrman HE, et al. The association between chronic illness, multimorbidity and depressive symptoms in an Australian primary care cohort. Social psychiatry and psychiatric epidemiology. 2012;47(2):175-84.

3. Anwar N, Kuppili PP, Balhara YPS. Depression and physical noncommunicable diseases: the need for an integrated approach. South-East Asia journal of public health. 2017;6(1):12.

4. Bădescu S, Tătaru C, Kobylinska L, Georgescu E, Zahiu D, Zăgrean A, et al. The association between Diabetes mellitus and Depression. Journal of medicine and life. 2016;9(2):120.

5. AHA. Depression and Heart Health Web Site 2012 [cited 2012. Available from: http://www.heart.org/HEARTORG/Condi tions/More/MyHeartandStrokeNews/Dep ression-and-HeartHealth_UCM_440444_Article.jsp.

6. Holt RI, De Groot M, Golden SH. Diabetes and depression. Current diabetes reports. 2014;14(6):491.

7. Goldberg D. The detection and treatment of depression in the physically ill. World Psychiatry. 2010;9(1):16-20.

8. Commonwealth. Non communicable diseases in Rwanda 2013 [Available from: http://www.commonwealthhealth.org/afri ca/rwanda/non_communicable_diseases_i n_rwanda/.

9. WHO. Country Cooperation strategy Rwanda 2009-2013. 2009.

10. Karinganire. Non communicable Diseases in Rwanda. 2012 [Available from: http://focus.rw/wp/2012/10/mentalhealth-day-focuses-on-depression.

11. Chow SC, Shao J, Wang H. Sample Size Calculations in Clinical Research. New York: Marcel Dekker; 2003.

12. APA Practice guideline for the treatment of patients with major depressive disorder. Washington DC: American Psychiatric Associarion; 2010

13. Zhang $\mathrm{W}, \mathrm{Xu} \mathrm{H}$, Zhao S, Yin S, Wang $\mathrm{X}$, Guo $J$, et al. Prevalence and influencing factors of co-morbid depression in patients with type 2 diabetes mellitus: a General Hospital based study. Diabetology \& metabolic syndrome. 2015;7(1):1-9.

14. Sweileh WM, Abu-Hadeed HM, Al-Jabi SW, Sa'ed HZ. Prevalence of depression among people with type 2 diabetes mellitus: a cross 
sectional study in Palestine. BMC public health. 2014;14(1):163.

15. Igwe $M$, Uwakwe $R$, Ahanotu $C$, Onyeama G, Bakare M, Ndukuba A. Factors associated with depression and suicide among patients with diabetes mellitus and essential hypertension in a Nigerian teaching hospital. African health sciences. 2013;13(1):68-77.

16. Raval A, Dhanaraj E, Bhansali A, Grover S, Tiwari P. Prevalence \& determinants of depression in type 2 diabetes patients in a tertiary care centre. 2010.

17. Khuwaja AK, Lalani S, Dhanani R, Azam IS, Rafique G, White F. Anxiety and depression among outpatients with type 2 diabetes: A multi-centre study of prevalence and associated factors. Diabetol Metab Syndr. 2010;2:72.

18. Islam SMS, Ferrari U, Seissler J, Niessen L, Lechner A. Association between depression and diabetes amongst adults in Bangladesh: a hospital based case-control study. Journal of global health. 2015;5(2).

19. Das R, Singh O, Thakurta RG, Khandakar M, Ali S, Mallick AK, et al. Prevalence of depression in patients with type II diabetes mellitus and its impact on quality of life. Indian journal of psychological medicine. 2013;35(3):284.

20. Khan ZD, Lutale J, Moledina SM. Prevalence of Depression and Associated Factors among
Diabetic Patients in an Outpatient Diabetes Clinic. Psychiatry journal. 2019;2019.

21. Aboshaiqah AE. Correlates of Depression among Patients Diagnosed with Chronic Illnesses in Saudi Arabia. Health. 2014;2014.

22. Arambewela MH, Somasundaram NP, Jayasekara HBPR, Kumbukage MP. Prevalence of Depression and Associated Factors among Patients with Type 2 Diabetes Attending the Diabetic Clinic at a Tertiary Care Hospital in Sri Lanka: A Descriptive Study. Psychiatry Journal. 2019;2019.

23. Rahman M, Rahman M, Flora M, Karim R, Zaman M. Depression and its association with socio-demographic characteristics among type 2 diabetes mellitus patients of Bangladesh. Mymensingh medical journal: MMJ. 2012;21(3):490-6.

24. El Mahalli AA. Prevalence and predictors of depression among type 2 diabetes mellitus outpatients in Eastern Province, Saudi Arabia. International journal of health sciences. 2015;9(2):119.

25. Habtewold TD, Alemu SM, Haile YG. Sociodemographic, clinical, and psychosocial factors associated with depression among type 2 diabetic outpatients in Black Lion General Specialized Hospital, Addis Ababa, Ethiopia: a cross-sectional study. $B M C$ psychiatry. 2016;16(1):103. 